Article

\title{
Designing Technologies with and for Youth: Traps of Privacy by Design
}

\author{
Bieke Zaman \\ Mintlab, Institute for Media Studies, KU Leuven, 3300 Leuven, Belgium; E-Mail: bieke.zaman@kuleuven.be
}

Submitted: 15 May 2020 | Accepted: 10 August 2020 | Published: 10 November 2020

\begin{abstract}
Media and communication scholars studying young people's privacy often involve them in research in order to better understand their interactions with digital technologies. Yet there is a lack of research on how, when, and why it makes sense to involve young people in the design phase of new technologies and how data protection safeguards can be taken proactively by design. By engaging with the body of literature at the intersection of media and communication studies, participatory design, and child-computer interaction research, this article discusses how youth-centred design efforts risk falling into three traps of privacy by design, relating to: 1) the different degrees of decision power within and between child-centred design guidelines and participatory design with young people; 2 ) the involvement of young people in design as citizens versus consumers; and 3 ) the conditions under which their participation in design is empowerment rather than mere decoration. The contribution of this article is a critical, sociotechnical reflection on the challenges and opportunities of involving young people in privacy by design decision-making. The article concludes by outlining an agenda for participatory design within an encompassing empowerment and digital citizenship framework that invites young people to reflect on who they want to be in a data-driven society.
\end{abstract}

\section{Keywords}

digital citizenship; empowerment; participatory design; personal data; privacy; privacy by design; youth

\section{Issue}

This article is part of the issue "Children's Voices on Privacy Management and Data Responsibilization" edited by Ralf De Wolf (Ghent University, Belgium) and Mariek Vanden Abeele (Tilburg University, The Netherlands).

(C) 2020 by the author; licensee Cogitatio (Lisbon, Portugal). This article is licensed under a Creative Commons Attribution 4.0 International License (CC BY).

\section{Introduction}

Media and communication scholars are consulting young people during research in order to better understand their unique notions of privacy. Little is known, however, about the research efforts that feed into the design of new technologies and the role that young people (can/should) take in these efforts. This is a missed opportunity, as research insights should not only have societal value for policy-making, education, and parenting but also inform the design of new digital technologies (Donoso, Verdoodt, Van Mechelen, \& Jasmontaite, 2016; Mainsah \& Morrison, 2012). Research insights can form the basis for decisions on how to implement technical safeguards of data protection and adapt digital technologies to young people's needs, competencies, and expectations. Young people have the right to be heard in all matters affecting them, including with respect to digital technologies, not only as consumers and data providers but also as active co-designers. This gives them the opportunity to question, negotiate, and gain a better understanding of privacy and data protection issues (Dowthwaite et al., 2020), which in turn creates a pathway to digital skill development for empowerment (D'Ignazio, 2017; Iversen, Smith, \& Dindler, 2018). The right of minors to be heard in all matters affecting them is a central premise of Article 12 of the United Nations Convention on the Right of the Child (UNCRC; United Nations, 1989). In UNICEF's comments on this provision, it is explained that this can be achieved either via direct consultation of young people or through a representative or an appropriate body (Viviers, 2014).

When designing digital technologies, companies generally consider the regulatory framework to be the maximum level of data protection, whereas the needs and expectations of Internet users go beyond these legal 
provisions (Culnan \& Williams, 2009; imec, 2019). Data protection regulation tells us what not to do with data, but gives little guidance on how to protect young people's interest and respect their rights by design (Lievens \& Verdoodt, 2018). Clearly, there are many social and ethical challenges at stake that research on and with young people can reveal. An example is the rich research insights that show how teenagers enjoy online public exposure and social prestige within what they perceive and co-construct as meaningful, intimate peer networks, outside parental control and beyond technical age limits (Balleys \& Coll, 2017; De Leyn, De Wolf, Abeele, \& De Marez, 2019; Lievens \& Verdoodt, 2018; Marwick \& boyd, 2014). A decade ago, Culnan and Williams (2009, p. 674) called upon organisations to not only pursue legal compliance but also to take up a moral responsibility to protect consumer data and avoid causing harm. They argued for a culture of privacy with managerial moral responsibility and accountability for the organization's privacy behaviours and the implications these may have for people personally.

Waiting for digital technologies to be launched before considering measures that would better protect young consumers' best interests, gives very little incentive to companies to implement change. The incentives for the end-user to take privacy matters into their own hands are also anything but attractive. Even though young people like having control of their personal data (Dowthwaite et al., 2020), they avoid the hassle needed to achieve this (Compañó \& Lusoli, 2010). People of all ages express paradoxical perceptions of responsibility for data protection, attributing responsibility to companies or to themselves (Fiesler \& Hallinan, 2018), even if they believe they do not have the necessary skills to do so (Compañó \& Lusoli, 2010). As it is difficult to make changes once technologies are on the market, both for companies and for users, more research is needed on how best to serve the interests of young people from the very beginning of the conceptualization and design of digital technologies. This would make it possible to take proactive rather than reactive measures.

Although involving young people in the design of new technologies is a key value in the field of childcomputer interaction research (Kawas et al., 2020), little attention has been given on how to engage them in decision-making with respect to privacy and data protection (Hourcade et al., 2017). Child-computer researchers have called for privacy issues to be addressed more explicitly by adopting a participatory and multidisciplinary perspective (Hourcade et al., 2018). Privacy researchers in both computer sciences and social sciences have arrived at a similar conclusion: Privacy is not simply a technical matter, it must be understood in terms of situated and collective, networked practices (Dourish \& Anderson, 2006; Marwick \& boyd, 2014). In order to (re)consider privacy in the context of today's technological affordances, as this article will further argue, insights from science and technology must be combined with media and communication studies in a participatory approach that accounts for the views and experiences of young people.

In response, this article provides a critical sociotechnical reflection on the potential of young people as codesigners of a youth-friendly, privacy-sensitive digital future. Based on the insights in the fields of participatory design, child-computer interaction research, and media and communication studies, three traps of privacy by design are identified. In what follows, this article discusses for each trap where and why the involvement of young people in design presents challenges and opportunities. The findings will show that young people's involvement in privacy by design efforts is as much about the improved and better design outcomes that can lead to a better quality of life in the long term, as it is about how young people can benefit from the process of participating in design.

\section{Trap \#1: Questioning Where the Decision Power Resides}

Design decision-making is a matter of exercising power (Frauenberger, Good, Fitzpatrick, \& Iversen, 2015). It provides an opportunity for the redistribution of power by including the typical "have-nots" in shaping their future (Arnstein, 2019, p. 24). Design decision power generally resides in adults who develop and design technologies for young people and who create policies and regulations for their use. There are regulations relating to design that pay particular attention to the protection of personal data for those under the age of 18. Examples include the European Union's General Data Protection Regulation (European Parliament, 2016), the Children's Online Privacy Protection Act in the United States (Lievens \& Verdoodt, 2018), and child-centred design guidelines, such as the list of 16 'standards of age-appropriate design' of the UK's Information Commissioner's Office (ICO; Livingstone, 2019). Child-centred design guidelines are a good example of a knowledge dissemination format that can build a much-needed bridge between academia and practice (Donoso et al., 2016). It can also help to alleviate some of the difficulties implementing the data regulations into concrete design decisions that support young people's best interests (Dowthwaite et al., 2020; Lievens \& Verdoodt, 2018). For instance, the ICO's list promotes the protection of personal data, compliant with the GDPR and UNCRC, and documents concrete child-centred design principles revolving around issues of 'data minimisation,' 'transparency,' 'default settings,' and 'parental controls' (ICO, 2019). Child-centred design guidelines such as the ICO's are not neutral design resources. Even though they were introduced as "technology-neutral design principles and practical privacy features" (ICO, 2019, p. 16), they do serve as normative expectations about young people's interactions with technology (Yu, Stoilova, \& Livingstone, 2018). Each list of guidelines will always make certain aspects sig- 
nificant, while ignoring or giving less weight to other aspects and different values, for instance by emphasizing specific risks or opportunities. They implicitly or explicitly communicate what can be understood as acceptable and adequate media use. Even in the way design documentation seeks credibility, it is not neutral. Does it report on the consultation of experts (and what kind of experts) to justify the content? And to what extent were young people heard in this process? The answers to these questions reveal the extent to which these guidelines are an instrument in the hands of the typical haves or have-nots. Child-centred design guidelines are not fully prescriptive either. There will always be a dozen possible 'translations' in concrete design features, and hence this gives considerable room to exert influence. As long ago as 1985, computer ethics researcher James $\mathrm{H}$. Moor compared writing a computer programme with building a house: "No matter how detailed the specifications may be, a builder must make numerous decisions about matters not specified in order to construct the house" (Moor, 1985, p. 7). Reaching the right practical level is a challenging undertaking. If the guidelines are too specific, they lose their applicability to a broad realm of services; too abstract, they risk becoming opaque and hard to interpret. This difficult balance brings both challenges and opportunities. On the one hand, there is always a risk of getting lost in translation, because the design guidelines do not say how they should be translated into concrete design features, how to assess and choose from the different alternatives, or how to ensure and evaluate whether the design choices are sufficiently youth-friendly and future proof to embrace all possible use(r)s and transformations. On the other hand, openended design guidelines also offer opportunities because they give flexibility for those involved in the design process to respond to cultural practices and context-specific demands (Nissenbaum, 2010). If open-endedness is built into the final design, then it also lowers the barriers for people to appropriate digital technology, as a codesigner during use.

In order to overcome the translation and implementation challenges mentioned above, previous research has argued for the participation of young people in design efforts. This would avoid overly adult-oriented interpretations and ensure that privacy by design choices are meaningful, attractive, and understandable to young people (Dowthwaite et al., 2020; Lievens \& Verdoodt, 2018; Wauters, Donoso, \& Lievens, 2014). Next to pragmatic considerations, the involvement of people in design can also be driven by a moral commitment to redistribute decision-making power. The latter approach has been amply described in the field of participatory design research. Its roots are situated in the political economy and worker's movement of the 1960s and 1970s in Scandinavian countries. It built on the premise that people who must live with the consequences of the introduction of technologies have the right to influence the changing conditions. Since its ear- ly years, the scope of participatory design research has been expanded by moving beyond the work context (Halskov \& Hansen, 2015), and by diversifying collaboration, including research with young people as design stakeholders (see e.g., Druin, 1998; Markopoulos, Read, MacFarlane, \& Hoysniemi, 2008). Notwithstanding more than 30 years of research on participatory design, there is a lack of a shared definition of what exactly it is. The field is characterized by a great diversity of design practices (Halskov \& Hansen, 2015) that build on a number of common key features. One of those common characteristics being the use of participatory methods as a means to give people influence on design decisions (Halskov \& Hansen, 2015). It provides an alternative model to the hierarchical expert (adult) versus (child) user power relations (Cumbo, Eriksson, \& Iversen, 2019). Participatory design is more than the mere involvement of people in design; it is primarily a political commitment that "places the power of defining and reshaping use situations" in the hands of those affected by the technologies, "allowing them to transform their own lives" (Halskov \& Hansen, 2015, pp. 89-90). In doing so, participatory design pursues change. In the narrowest sense, change refers to the exploration of design alternatives that could yield improved or better products. Beyond the product focus, there is also a concern about the benefits of participation in the process, for instance linked to learning opportunities. In the broadest sense, participatory design has become increasingly concerned with exploring the role of technologies in improving the quality of life (Halskov \& Hansen, 2015).

Within the diversity of participatory design practices, we discern various levels of participatory power depending on who (e.g., which young person is recruited?) is participating; why (e.g., to create a better product or because young people have the right to be heard?); how (e.g., which role do young people take in the design process?); to what extent (e.g., how is decision power shared between young people and adults?); and with what gains (e.g., how do young people benefit from participation?). In addition, we can distinguish between approaches that only focus on people's agency in the design and production of new technologies, and participatory design that continues when the project funding ends and that is also concerned with people's agency during use and consumption. Traditionally, participatory design typically involved young people in one or more iterative design phases aiming at a better or improved end product or system. The participation then finished with the creation of a product or system, as a rather fixed result developed within the project time. This contrasts with participatory design processes that fully account for the sociotechnical processes that unfold over the long term; here participation is seen as an important condition of building an ongoing, dynamic infrastructure, which does not finish when the project ends. This long-term perspective unfolds the range of activities for co-shaping technological affordances, from design time 
to ongoing design practices during use and consumption (Bjögvinsson, Ehn, \& Hillgren, 2012; Löwgren \& Reimer, 2013). Media scholars have linked the latter practices under the umbrella of young people's 'rights by design,' which allow them, for instance, to check, rectify, erase, or edit personal data (Yu et al., 2018). Lievrouw (2006) theorizes this as design opportunities for creatively reconfiguring the technological artefacts and for remediating content and forms of interaction practices. Similar voices emanate from international organisations, including companies, as part of an initiative that sets out the principles for a safer and more empowering positive future, led by Tim Berners-Lee. It includes principles that explicitly call upon adaptation, appropriation, and redesign practices that are part of the design in use time. As part of their proposed 'Contract for the Web,' people are invited to be engaged as co-creators, actively shaping online content and systems and building strong online communities (Contract for the Web, 2019). Approaching people as co-creators is also relevant in the context of privacy by design, "because contexts shift and overlap over time, privacy is an ongoing, active practice" (Marwick \& boyd, 2014 , p. 1062). Young people are active agents in this process, as they co-construct and give active meanings to privacy norms and contexts, not only during the design time of new technologies (Dowthwaite et al., 2020) but also as part of the use time once the technologies have been implemented (De Leyn et al., 2019; Marwick \& boyd, 2014; Steijn \& Vedder, 2015).

In sum, with the identification of the first trap, we made explicit that there are differences both within and between child-centred design guidelines and participatory design efforts, and that these differences reveal where the design decision-making power resides. We discussed that although design guidelines can create youth-centred sensitivities that feed into design decision-making, they should not be understood as a prescriptive list telling us exactly what to design. Considering how we can design for and with young people, we pointed to the importance of embracing young people's rights by design, not only as part of their consumption and use of technologies, but also during the conceptualization and design of these technologies before their actual implementation.

\section{Trap \#2: Young People Are More Likely to Participate in Design as Consumers Than as Citizens}

As part of the second trap, this article elucidates how the different manifestations of participatory design are likely to boil down to an involvement of young people as consumers instead of citizens. One way of seeking genuine participation is to engage young people as citizens. Such an approach is being advocated in a reinvigorated research strand on participatory design concerned with building dynamic infrastructures that enable longterm engagement in a project or with respect to a societal issue (Bjögvinsson et al., 2012) through the formation of publics, for instance by matchmaking citizens with local organisations and governments, and by fostering civic engagement and building capacities to connect to, set up, and sustain communities (Le Dantec \& DiSalvo, 2013; Le Dantec \& Fox, 2015; Mainsah \& Morrison, 2012). However, if young people are only involved because they represent the target group of the envisioned product, then we are likely to reach out to them in their economic role instead of that as a citizen. Their economic position can point to their role as a future consumer, future producer co-shaping infrastructural elements, or as future data provider (van Dijck, 2009). The reasoning then goes that if young people, as experts of their own lives, are given a voice in the design of products they will eventually use, we are likely to increase future adoption and create more successful (read: more useful and economically viable/competitive) products.

If 'learning from youth' is the only reason young people are involved, then we must face its downsides. Simply inviting young people to deliver ideas and inform us how they perceive issues of privacy management, and then stopping their participation once we have 'taken' from them what we need for research is not an empowered form of participation (Zimmerman, 2000). In a commercial setting, co-creation creates a tension between people's voices enabled by the professional entities versus those who are exploited for their ideas or labour (Banks \& Humphreys, 2008; van Dijck, 2009). While academic research goes through a rigorous process of ethical reviewing, commercial participatory design projects in industry do not (Hourcade et al., 2017). The involvement of young people in the design process may even create datafied users before technologies are on the market and under regulatory scrutiny. Nowadays, the spheres in which participatory design unfold no longer operate in isolation from each other. The neoliberal 21st century research and technology commercialization ecosystem pursues innovation through collaboration and co-creational interactions that group industry, university, government, and societal stakeholders to better align commercialization efforts with the needs of society (Markman, Siegel, \& Wright, 2008; McAdam, Miller, \& McAdam, 2018). It remains to be seen how and whether the latter evolution serves the interests of young people.

Unfortunately, many design projects in which young people participate are in fact nothing more than a 'crowdsourcing of ideas' (Read, Fitton, Sim, \& Horton, 2016). This reminds us of the 'work as play' trap and the technology-discourses that circulated in the geek culture of the digital creative industries that built on the volunteerism and digital labour of early adopters, enthusiasts, and hobbyists who loved to tinker with media (van Dijck, 2009, p. 51). Furthermore, the commercial context is dominated by a technocratic view on innovation that trumps social innovation and that promotes what Morozov (2013, p. 6) refers to as 'technological solutionism': the "unhealthy preoccupation with sexy, monumental, and narrow-minded [computational] 
solutions - the kind of stuff that wows audiences at TED Conferences-to problems that are extremely complex, fluid, and contentious." Technology design would therefore benefit from a holistic understanding of the problem space, to which participatory design research can contribute, because "what many solutionists may presume to be 'problems' in need of solving are not problems at all" (Morozov, 2013, p. 6). Morozov warns against technoutopian discourses that suggest that technologies will save the world, just as he warns against unintended consequences of technological solutionism. As far as research into privacy by design is concerned, there is a possible (intended or unintended) side effect, namely that the mere involvement of young people would make them responsible for finding solutions to privacy issues or even relieve institutional responsibility. This would fall into the same trap as many technical and legal discourses around privacy that have made the individual responsible for maintaining control over personal data, even when it is clear that users do not fully understand what they are giving permission to and that people suffer from consent fatigue (Royakkers, Timmer, Kool, \& van Est, 2018). Simply striving to improve the accessibility and readability of privacy policies and terms and conditions is not enough, as it still passes the responsibility for making informed choices on to the end-users (Fiesler \& Hallinan, 2018). The current networked privacy context makes the focus on the individual untenable (Marwick \& boyd, 2014). Therefore, privacy by design must be holistically understood as the mutually constitutive interactions between and among the people who use technologies as well as the platforms, third parties, policymakers, educators, and regulators who are all embedded in particular data practices. We must also refrain from reducing privacy to a micro-level concern as if the 'problem' and 'solution' is only to be found in design properties. Economic, governance, and cultural issues play a role in shaping any privacy by design effort. A multistakeholder and multi-layered notion of privacy is thus needed to respond to the societal and technical complexity and messiness of today's data-driven society (Barassi, 2018; van Dijck, 2009). Just like techno-utopian discourses can cause blind spots, so too techno-dystopian discourses and media panics have side effects. The latter discourses may incite companies to take actions to protect young people against what adults see as risks, which is not always experienced as such by young people themselves (Lobel, Granic, Stone, \& Engels, 2014). It may even prompt companies to stop offering their services to young people altogether, thereby thwarting their digital participation rights (Lievens \& Verdoodt, 2018).

Applauding participatory design with young people to some extent mirrors how we have hailed the surge of young people using the digital space as part of the participatory culture (van Dijck, 2009). If we draw lessons from how the participatory culture has evolved, we learn that a transformation has taken place, whereby participatory media have transformed from small initiatives towards a mastodon ecosystem of media conglomerates. Similarly, for the first research-driven participatory design projects that operated on a small scale, it was easier to pursue safeguards for democratic participation, both with respect to processes and outcomes. In contrast, today, with digital platforms that place young people's media consumption practices in the hands of big tech giants (van Dijck, 2009), the question is whether and how participatory design must follow and be adjusted to this new complexity (Bannon, Bardzell, \& Bødker, 2018). Just like the participatory culture promoted by Web 2.0 did not succeed in opening real possibilities for democratic empowerment (Barassi, 2017), so might we question whether today's participatory design efforts risk falling victim to corporate exploitation of user's digital production and to biases caused by fake and commodified forms of empathy with the end-user (Robertson \& Allen, 2018). Moreover, with technologies increasingly controlling life for us, the design choices underlying them risk promoting technological paternalism whereby, at design time and through design, what is best is decided, with less control for the diverse user group to make it work for them in a meaningful way (Royakkers et al., 2018, p. 131). Floridi (2014, p. 190) similarly argues "that ethics by design may be mildly paternalistic, insofar as it privileges the facilitation of the right kind of choices, actions, process, or interactions on behalf of the agents involved." In response, Floridi calls for 'pro-ethical design,' which privileges facilitation of reflection instead of the search for the 'right' choices.

In sum, with the identification of a second trap, this article argued that young people are more likely to participate in design as consumers than as citizens, and pointed to problematic discourses and practices when the sole motivation to involve young people in design is pragmatic and functionalist driven. Continuing the line of thought developed earlier that design guidelines can never be fully prescriptive, this statement is now reconsidered by positing that design guidelines must never be prescriptive either, but for ethical reasons. Deciding upon the 'right' privacy options for and by design, includes the risk of taking rigid moral decisions on what is right or best. Even when driven by good intentions, designing for good can mean different things for different people. Especially as by 'othering' those for whom the product is designed, as people in need of help, we easily risk being paternalistic (Vandenberghe \& Slegers, 2016). Participatory design, then, should instead be seen as an opportunity to negotiate design options for continued meaning-making and for reflection by diverse user groups, rather than a momentary act to arrive at a single and fixed solution.

\section{Trap \#3: Young People's Participation in Design is More Often an Act of Decoration Than of Empowerment}

An analysis of the last decade of research on the design of technologies for and with young people has revealed that more research is needed to understand how partici- 
pation in design is linked to empowerment (Kawas et al., 2020). The third and last trap aims to address this issue by discussing the differences between acts and outcomes of empowerment versus decoration. Genuine participation should imply giving a certain degree of decisionmaking power to young people and to be, therefore, more than a tokenistic assurance that they will hear and be heard-without any ability to influence or change (Arnstein, 2019; Hart, 2008). In design, this would enable young people to negotiate the issues that concern them, by creating and deciding upon design choices (Wagner, 2018; Zimmerman, 2000). This boils down to empowerment as 'inclusion' in decision-making processes (Floridi, 2014). Additionally, we can think of empowerment in the 'more opportunities' sense, that is empowerment as 'improvement' (Floridi, 2014). The latter is pursued if the involvement of young people as co-designers aims for both a higher quantity of available choices and a higher quality of opportunities. Empowerment-led forms of participatory design resemble action research. They both build on an agentic notion of non-academic people, including youths, acknowledging their right and capacity to actively participate in research on topics that matter to them. Moreover, both action research and participatory design share a similar moral commitment to explore alternatives and possibilities for change through the participation in and outcomes of the research (Frauenberger et al., 2015; Kemmis, McTaggart, \& Nixon, 2014). The envisioned change is typically linked to social and educational values that the research participants can benefit from. Both in action research and participatory design, researchers use terms as 'empowerment,' 'gains,' 'benefits,' 'democracy,' and 'mutual/collaborative learning' to describe the goals of their participatory research endeavours (see e.g., Donoso et al., 2016; Frauenberger et al., 2015; Halskov \& Hansen, 2015; Iversen et al., 2018; Kemmis et al., 2014; Kinnula et al., 2017; Schepers, Dreessen, \& Zaman, 2018b). From the perspective of empowerment theory, the impact of change can be situated at the individual, community, and/or organisational levels (Zimmerman, 2000). Most empowerment efforts pursue individual benefits, for instance, linked to acquiring decision-making skills or critical awareness (Zimmerman, 2000). Although participatory design projects have also mainly been concerned with individual empowerment (Bjögvinsson et al., 2012), we are witnessing an increased interest in organizational and community concerns (Le Dantec \& DiSalvo, 2013; Le Dantec \& Fox, 2015; Mainsah \& Morrison, 2012).

Empowerment theory not only accounts for individual, organizational, and community levels, and empowerment as inclusion versus empowerment as improvement, it also distinguishes between the 'empowering' processes and being 'empowered' as an outcome (Zimmerman, 2000). In the field of participatory design, both aspects have been addressed, with researchers investigating the empowering potential of the methods and procedures of participation in design as well as the positive change that is envisioned with it (see e.g., Halskov \& Hansen, 2015; Iversen, Smith, \& Dindler, 2017; Schepers, Dreessen, \& Zaman, 2018a; Schepers et al., 2018b). Both processes and outcomes should not be understood as momentary acts, or as individual one-off events. From the very outset, the participatory design community was built on the principle of dialectical exchanges and mutual learning (Bratteteig, Bødker, Dittrich, Mogensen, \& Simonsen, 2013; Halskov \& Hansen, 2015). This implies a commitment to the involvement of people in design, as well as a commitment to give something back. In and through participatory design with young people, researchers and designers learn about young people's opinions, perceptions and experiences, and their situated actions. By opening up dialogue, adults learn about the particularities of youth culture in which privacy is perceived and negotiated. Young people, in turn, through their participation in research and design, acquire new competencies, such as the knowledge, skills, and attitudes to critically and constructively engage with technology, which Iversen et al. (2018) have called 'computational empowerment.' In line with empowerment theory, computational empowerment builds on a moral commitment to co-create positive change and identify strengths, which is more than just ameliorating negative aspects or identifying risks. As computational empowerment accounts for the educational aspects of engagement with technologies, as well as the economic and civic/political opportunities, this article argues, it is an important steppingstone towards digital citizenship. Building on a review of over 35 frameworks on youth and digital citizenship over the world, Cortesi, Hasse, Lombana, Kim, and Gasser (2020) have put forward a definition for what they term 'digital citizenship+ (plus),' that is, "the skills needed for youth to participate fully academically, socially, ethically, politically, and economically in our rapidly evolving digital world" (p. 28). Through co-design activities with young people, Cortesi et al. (2020) mapped 17 interconnected areas of life that they believe youth digital citizenship programmes should address, including amongst others artificial intelligence, civic and political engagement, computational thinking, data, and privacy and reputation. As it is an encompassing, balanced term, open for contextualized interpretations, it holds the potential to provide a valuable framework for future contributions in the realm of privacy by design theory and practice.

By identifying the third trap, this article aims to reverse the trend that young people's participation in design is more often an act of decoration than of empowerment. This would require reflection on both the processes and outcomes of the involvement of young people ("are these empowering processes resulting in young people being empowered?"), the flavour of being empowered (in a sense of both inclusion and improvement), as well as a consideration of both the challenges and opportunities for digital citizenship that reside and interact at an individual, organizational, and community level. 


\section{Conclusions}

The rationale for this article followed from the observation that most media and communication studies dealing with youth and privacy have only been concerned with hearing young people's voices regarding their interaction with existing technologies. Yet, considering the timeline of a technology's trajectory, this article argued that we should not only study (the broad array of societal changes that may arise from) the adoption and use of digital technologies but also consider how design decisions are being made prior to their implementation (see also e.g., Bailey \& Barley, 2020). This would give scholars opportunities to support young people's best interests proactively rather than reactively when privacy issues are flagged, e.g., by legislative bodies or through bad publicity (Culnan \& Williams, 2009; Fiesler \& Hallinan, 2018). This article aimed to address the gap in research on how, when, and why it makes sense to involve young people in design decision-making prior to the implementation of digital technologies. It did so by engaging with literature from existing schools of thought that speak to media and communication as well as to disciplines concerned with the (participatory) design, evaluation, and implementation of interactive computing systems. The contribution of this article revolves around the identification of three traps of privacy by design. The first trap pointed to different degrees of decision power in relation to the use of child-centred guidelines and participatory design research with young people. The second trap revealed the wide variety of approaches that all fit within the umbrella term of participatory design, but that differ in whether they involve young people as consumers or citizens. Finally, the third trap made clear how participatory design with young people can serve empowerment rather than being a decoration.

In conclusion, it is argued that participatory design situated within an encompassing empowerment and digital citizenship framework is a future-proof direction beneficial to young people. In today's increasingly complex and messy digital society, we must not blindly focus on the question of whether young people have comprehensive knowledge (see also Article 12 of the UNCRC) of the privacy issues at stake. We must also move beyond the discussion of whether young people can really implement change at the levels of commercial and institutional privacy, areas that they are not immediately concerned with (Steijn \& Vedder, 2015), and that rather call for a reflection on data governance strategies on a macro level. In a world where humans are increasingly losing power and control to machines, and where even adults and the traditional institutes have a hard time following the rapid pace of technology, it is more beneficial to rethink our traditional notions of participatory design, as the entire 'human-centred design' logic seems to be at odds with current developments. Rather than seeking input through participative design with young people on what must be designed, and deciding upon the 'right' design choices, it is more fruitful to seek an answer to the question of what kind of society we want regarding our interaction with technology (Frauenberger, 2019), as well as how we can build in mechanisms for an ongoing reflection on this compelling question (Floridi, 2014), both during design in production time and during design in use and consumption. This approach would also help us to reflect on how privacy issues are interlinked with other public values, that is not only with the value of security-as amply covered in public debates-but also with public values that are given less attention, such as autonomy, human dignity, and control (Royakkers et al., 2018, p. 128). Future researchers and designers are therefore called upon to take the unique meaningmaking processes and experiences of young people as a starting point, not only to improve or mitigate risky, harmful, and undesirable (privacy-related) design issues, but also to facilitate a contextualized reflection on who young people want to be in a data-driven society.

\section{Acknowledgments}

I am grateful to Selina Schepers, Marije Nouwen, Jessica Schoffelen, Luciana Monteiro Krebs, Katleen Gabriels, Bert Vandenberghe, Mariek Vanden Abeele, Ralf De Wolf, Timothy Kariotis and the anonymous reviewers for their inspiration.

\section{Conflict of Interests}

The authors declare no conflict of interests.

\section{References}

Arnstein, S. R. (2019). A ladder of citizen participation. Journal of the American Planning Association, 85(1), 24-34. https://doi.org/10.1080/ 01944363.2018 .1559388

Bailey, D. E., \& Barley, S. R. (2020). Beyond design and use: How scholars should study intelligent technologies. Information and Organization, 30(2), 100286. https://doi.org/10.1016/j.infoandorg.2019.100286

Balleys, C., \& Coll, S. (2017). Being publicly intimate: Teenagers managing online privacy. Media, Culture \& Society, 39(6), 885-901. https://doi.org/10.1177/ 0163443716679033

Banks, J., \& Humphreys, S. (2008). The labour of user co-creators: Emergent social network markets? Convergence: The International Journal of Research into New Media Technologies, 14(4), 401-418. https:// doi.org/10.1177/1354856508094660

Bannon, L., Bardzell, J., \& Bødker, S. (2018). Reimagining participatory design. Interactions, 26(1), 26-32. https://doi.org/10.1145/3292015

Barassi, V. (2017). BabyVeillance? Expecting parents, online surveillance and the cultural specificity of pregnancy apps. Social Media + Society, 3(2), 1-10. https://doi.org/10.1177/2056305117707188 
Barassi, V. (2018). The child as datafied citizen: Critical questions on data justice in family life. In G. Mascheroni, A. Jorge, \& C. Ponte (Eds.), Digital parenting: The challenges for families in the digital age (pp. 169-177). Gothenburg: Nordicom. https:// research.gold.ac.uk/23737

Bjögvinsson, E., Ehn, P., \& Hillgren, P.-A. (2012). Design things and design thinking: Contemporary participatory design challenges. Design Issues, 28(3), 101-116. https://doi.org/10.1162/DESI_a_00165

Bratteteig, T., B $\varnothing$ dker, K., Dittrich, Y., Mogensen, P. H., \& Simonsen, J. (2013). Methods: Organising principles and general guidelines for participatory design projects. In J. Simonsen \& T. Robertson (Eds.), Routledge international handbook of participatory design (p. 117). Abingdon: Routledge. https://www.bookdepository.com/RoutledgeInternational-Handbook-Participatory-DesignJesper-Simonsen/9780415720212

Compañó, R., \& Lusoli, W. (2010). The policy maker's anguish: Regulating personal data behavior between paradoxes and dilemmas. In T. Moore, D. Pym, \& C. Ioannidis (Eds.), Economics of information security and privacy (pp. 169-185). Boston, MA: Springer US. https://doi.org/10.1007/978-1-4419-6967-5_9

Contract for the Web. (2019). Contract for the Web. Washington, DC: Contract for the Web. Retrieved from https://9nrane41lq4966uwmljcfggvwpengine.netdna-ssl.com/wp-content/uploads/ Contract-for-the-Web-3.pdf

Cortesi, S. C., Hasse, A., Lombana, A., Kim, S., \& Gasser, U. (2020). Youth and digital citizenship+ (plus): Understanding skills for a digital world (Research Paper No. 2020-2). Cambridge, MA: Berkman Klein Center for Internet \& Society. http://dx.doi.org/10.2139/ ssrn. 3557518

Culnan, M. J., \& Williams, C. C. (2009). How ethics can enhance organizational privacy: Lessons from the Choicepoint and TJX data breaches. MIS Quarterly, 33(4), 673. https://doi.org/10.2307/20650322

Cumbo, B. J., Eriksson, E., \& Iversen, O. S. (2019). The "least-adult" role in participatory design with children. In A. Lugmayr, M. Masek, M. Reynolds, \& M. Brereton (Eds.), Proceedings of the 31st Australian Conference on Human-ComputerInteraction (pp. 73-84). New York, NY: Association for Computing Machinery. https://doi.org/10.1145/ 3369457.3369464

De Leyn, T., De Wolf, R., Abeele, M. V., \& De Marez, L. (2019). Reframing current debates on young people's online privacy by taking into account the cultural construction of youth. In A. Gruzd, P. Mai, \& P. Kumar (Eds.), Proceedings of the 10th International Conference on Social Media and Society: SMSociety '19 (pp. 174-183). New York, NY: Association for Computing Machinery. https://doi.org/10.1145/ 3328529.3328558

D'Ignazio, C. (2017). Creative data literacy: Bridging the gap between the data-haves and data-have nots. Information Design Journal, 23(1), 6-18. https://doi. org/10.1075/idj.23.1.03dig

Donoso, V., Verdoodt, V., Van Mechelen, M., \& Jasmontaite, L. (2016). Faraway, so close: Why the digital industry needs scholars and the other way around. Journal of Children and Media, 10(2), 200-207. https://doi.org/10.1080/17482798.2015.1131728

Dourish, P., \& Anderson, K. (2006). Collective information practice: Exploring privacy and security as social and cultural phenomena. Human-Computer Interaction, 21(3), 319-342. https://doi.org/10.1207/ s15327051hci2103_2

Dowthwaite, L., Creswick, H., Portillo, V., Zhao, J., Patel, M., Perez Vallejos, E., . . . Jirotka, M. (2020). "It's your private information. It's your life.": Young people's views of personal data use by online technologies. In E. Rubegni \& A. Vasalou (Eds.), Proceedings of the Interaction Design and Children Conference (pp. 121-134). New York, NY: Association for Computing Machinery. https://doi.org/10.1145/ 3392063.3394410

Druin, A. (Ed.). (1998). The design of children's technology. San Francisco, CA: Morgan Kaufmann.

European Parliament. (2016). Regulation (EU) 2016/679 of the European Parliament and of the Council of 27 April 2016 on the protection of natural persons with regard to the processing of personal data and on the free movement of such data, and repealing Directive 95/46/EC (General Data Protection Regulation. Brussels: European Parliament. Retrieved from https://eur-lex.europa.eu/legal-content/EN/ TXT/?qid=1532348683434\&uri=CELEX:02016R067920160504

Fiesler, C., \& Hallinan, B. (2018). "We are the product": Public reactions to online data sharing and privacy controversies in the media. In R. Mandryk \& M. Hancock (Eds.), Proceedings of the $2018 \mathrm{CHI}$ conference on Human Factors in Computing Systems: $\mathrm{CHI}$ '18 (pp. 1-13). New York, NY: Association for Computing Machinery. https://doi.org/10.1145/ 3173574.3173627

Floridi, L. (2014). The 4th revolution: How the infosphere is reshaping human reality (1st ed.). Oxford: Oxford University Press.

Frauenberger, C. (2019). Entanglement $\mathrm{HCl}$ the next wave? ACM Transactions on Computer-Human Interaction, 27(1), 1-27. https://doi.org/10.1145/3364998

Frauenberger, C., Good, J., Fitzpatrick, G., \& Iversen, 0. S. (2015). In pursuit of rigour and accountability in participatory design. International Journal of HumanComputer Studies, 74, 93-106. https://doi.org/ 10.1016/j.ijhcs.2014.09.004

Halskov, K., \& Hansen, N. B. (2015). The diversity of participatory design research practice at PDC 20022012. International Journal of Human-Computer Studies, 74, 81-92. https://doi.org/10.1016/j.ijhcs. 2014.09.003 
Hart, R. A. (2008). Stepping back from 'the ladder': Reflections on a model of participatory work with children. In A. Reid, B. B. Jensen, J. Nikel, \& V. Simovska (Eds.), Participation and learning (pp. 19-31). Dordrecht: Springer Netherlands. https://doi.org/10.1007/9781-4020-6416-6 2

Hourcade, J. P., Zeising, A., Antle, A. N., Anthony, L., Fails, J. A., Iversen, O. S., . . . Walsh, G. (2018). Childcomputer interaction, ubiquitous technologies, and big data. Interactions, 25(6), 78-81. https://doi.org/ $10.1145 / 3274572$

Hourcade, J. P., Zeising, A., Iversen, O. S., Pares, N., Eisenberg, M., Quintana, C., \& Skov, M. B. (2017). Childcomputer interaction SIG: Ethics and values. In G. Mark \& S. Fussell (Eds.), Proceedings of the 2017 CHI conference Extended Abstracts on Human Factors in Computing Systems: CHI EA '17 (pp. 1334-1337). New York, NY: Association for Computing Machinery. https://doi.org/10.1145/3027063.3049286

imec. (2019). imec.Al barometer. Leuven: Imec. Retrieved from https://www.imec-int.com/drupal/ sites/default/files/inline-files/Al-meter.pdf

Information Commissioner's Office. (2019). Age appropriate design: A code of practice for online services (No. 20190412). Wilmslow: Information Commissioner's Office. Retrieved from https://ico.org.uk/ media/about-the-ico/consultations/2614762/ageappropriate-design-code-for-public-consultation.pdf

Iversen, O. S., Smith, R. C., \& Dindler, C. (2017). Child as protagonist: Expanding the role of children in participatory design. In P. Blikstein \& D. Abrahamson (Eds.), Proceedings of the 2017 conference on Interaction Design and Children: IDC '17 (pp. 27-37). New York, NY: Association for Computing Machinery. https:// doi.org/10.1145/3078072.3079725

Iversen, O. S., Smith, R. C., \& Dindler, C. (2018). From computational thinking to computational empowerment: A 21st century PD agenda. In L. Huybrechts, M. Teli, A. Light, Y. Lee, J. Garde, J. Vines, . . . K. Bødker (Eds.), Proceedings of the 15th Participatory Design Conference on Full Papers: PDC'18 (pp. 1-11). New York, NY: Association for Computing Machinery. https://doi.org/10.1145/3210586.3210592

Kawas, S., Yuan, Y., DeWitt, A., Jin, Q., Kirchner, S., Bilger, A., . . Y Yarosh, S. (2020). Another decade of IDC research: Examining and reflecting on values and ethics. In E. Rubegni \& A. Vasalou (Eds.), IDC '20: Proceedings of the Interaction Design and Children Conference (pp. 205-215). New York, NY: Association for Computing Machinery. https://doi.org/10.1145/ 3392063.3394436

Kemmis, S., McTaggart, R., \& Nixon, R. (2014). The action research planner. Singapore: Springer. https://doi. org/10.1007/978-981-4560-67-2

Kinnula, M., Livari, N., Molin-Juustila, T., Keskitalo, E., Leinonen, T., Mansikkamäki, E., ... Similä, M. (2017). Cooperation, combat, or competence building: What do we mean when we are 'empowering children' in and through digital technology design? In Y. J. Kim, R. Agarwal, \& J. K. Lee (Eds.), Proceedings of the Thirty Eighth International Conference on Information Systems. Atlanta, GA: Association for Information Systems. Retrieved from https://aisel.aisnet. org/icis2017/TransformingSociety/Presentations/15

Le Dantec, C. A., \& DiSalvo, C. (2013). Infrastructuring and the formation of publics in participatory design. Social Studies of Science, 43(2), 241-264. https://doi. org/10.1177/0306312712471581

Le Dantec, C. A., \& Fox, S. (2015). Strangers at the gate: Gaining access, building rapport, and co-constructing community-based research. In D. Cosley \& A. Forte (Eds.), Proceedings of the 18th ACM Conference on Computer Supported Cooperative Work \& Social Computing-CSCW '15 (pp. 1348-1358). New York, NY: Association for Computing Machinery. https:// doi.org/10.1145/2675133.2675147

Lievens, E., \& Verdoodt, V. (2018). Looking for needles in a haystack: Key issues affecting children's rights in the general data protection regulation. Computer Law \& Security Review, 34(2), 269-278. https:// doi.org/10.1016/j.clsr.2017.09.007

Lievrouw, L. A. (2006). Oppositional and activist new media: Remediation, reconfiguration, participation. In G. Jacucci \& F. Kensing (Eds.), PDC '06: Proceedings of the ninth conference on Participatory design: Expanding boundaries in design-Volume 1 (pp. 115-124). New York, NY: Association for Computing Machinery. https://doi.org/10.1145/1147261.1147279

Livingstone, S. (2019, January 28). Children's personal privacy online: It's neither personal nor private. Media@LSE. https://blogs.Ise.ac.uk/medialse/2019/ 01/28/childrens-personal-privacy-online-its-neitherpersonal-nor-private

Lobel, A., Granic, I., Stone, L. L., \& Engels, R. C. M. E. (2014). Associations between children's video game playing and psychosocial health: Information from both parent and child reports. Cyberpsychology, Behavior, and Social Networking, 17(10), 639-643. https://doi.org/10.1089/cyber.2014.0128

Löwgren, J., \& Reimer, B. (2013). The cultural form of collaborative media. In J. Löwgren \& B. Reimer (Eds.), Collaborative media: Production, consumption, and design interventions (pp. 13-28). Cambridge, MA: MIT Press.

Mainsah, H., \& Morrison, A. (2012). Social media, design and civic engagement by youth: A cultural view. In K. Halskov, H. Winschiers-Theophilus, Y. Lee, J. Simonsen, \& K. Bødker (Eds.), Proceedings of the 12th Participatory Design Conference on Research Papers: Volume 1-PDC'12 (pp. 1-9). New York, NY: Association for Computing Machinery. https://doi.org/10.1145/ 2347635.2347637

Markman, G. D., Siegel, D. S., \& Wright, M. (2008). Research and technology commercialization. Journal of Management Studies, 45(8), 1401-1423. https:// doi.org/10.1111/j.1467-6486.2008.00803.x 
Markopoulos, P., Read, J., MacFarlane, S., \& Hoysnie$\mathrm{mi}$, J. (2008). Evaluating children's interactive products: Principles and practices for interaction designers. Boston, MA: Morgan Kaufmann.

Marwick, A. E., \& boyd, d. (2014). Networked privacy: How teenagers negotiate context in social media. New Media \& Society, 16(7), 1051-1067. https://doi. org/10.1177/1461444814543995

McAdam, M., Miller, K., \& McAdam, R. (2018). Understanding quadruple helix relationships of university technology commercialisation: A micro-level approach. Studies in Higher Education, 43(6), 1058-1073. https://doi.org/10.1080/03075079. 2016.1212328

Moor, J. H. (1985). What is computer ethics? Metaphilosophy, 16(4), 266-275. https://doi.org/10.1111/ j.1467-9973.1985.tb00173.x

Morozov, E. (2013). To save everything, click here: The folly of technological solutionism. New York, NY: PublicAffairs.

Nissenbaum, H. F. (2010). Privacy in context: Technology, policy, and the integrity of social life. Stanford, CA: Stanford Law Books.

Read, J. C., Fitton, D., Sim, G., \& Horton, M. (2016). How ideas make it through to designs: Process and practice. In S. Björk \& E. Eriksson (Eds.), Proceedings of the 9th Nordic Conference on Human-Computer Interaction: NordiCHI '16 (pp. 1-10). New York, NY: Association for Computing Machinery. https://doi.org/ $10.1145 / 2971485.2971560$

Robertson, R., \& Allen, P. (2018). Empathy is not evidence: Four traps of commodified empathy. In D. Nafus \& T. Rattenbury (Eds.), EPIC Proceedings (pp. 104-124). Oregon: EPIC. Retrieved from https:// www.epicpeople.org/intelligences

Royakkers, L., Timmer, J., Kool, L., \& van Est, R. (2018). Societal and ethical issues of digitization. Ethics and Information Technology, 20(2), 127-142. https://doi. org/10.1007/s10676-018-9452-x

Schepers, S., Dreessen, K., \& Zaman, B. (2018a). Rethinking children's roles in participatory design: The child as a process designer. International Journal of ChildComputer Interaction, 16, 47-54. https://doi.org/ 10.1016/j.ijcci.2017.12.001

Schepers, S., Dreessen, K., \& Zaman, B. (2018b). Exploring user gains in participatory design processes with vulnerable children. In L. Huybrechts, M. Teli, A. Light, Y. Lee, J. Garde, J. Vines, ... K. Bødker (Eds.), Proceedings of the 15th Participatory Design Conference on Short Papers, Situated Actions, Workshops and Tuto- rial: PDC '18 (pp. 1-5). New York, NY: Association for Computing Machinery. https://doi.org/10.1145/ 3210604.3210617

Steijn, W. M. P., \& Vedder, A. (2015). Privacy under construction: A developmental perspective on privacy perception. Science, Technology, \& Human Values, 40(4), 615-637. https://doi.org/10.1177/ 0162243915571167

United Nations. (1989). Convention on the rights of the child. New York, NY: United Nations. Retrieved from https://www.ohchr.org/en/professionalinterest/ pages/crc.aspx

Vandenberghe, B., \& Slegers, K. (2016). Designing for others, and the trap of $\mathrm{HCl}$ methods \& practices. In J. Kaye \& A. Druin (Eds.), Proceedings of the 2016 $\mathrm{CHI}$ Conference Extended Abstracts on Human Factors in Computing Systems (pp. 512-524). New York, NY: Association for Computing Machinery. https:// doi.org/10.1145/2851581.2892584

van Dijck, J. (2009). Users like you? Theorizing agency in user-generated content. Media, Culture \& Society, 31(1), 41-58. https://doi.org/10.1177/ 0163443708098245

Viviers, A. (2014). General comments of the committee on the rights of the child a compendium for child rights advocates, scholars and policy makers. New York, NY: UNICEF. Retrieved from https://www. unicef.org/southafrica/SAF_resources_ crcgeneralcomments.pdf

Wagner, I. (2018). Critical reflections on participation in design. In V. Wulf, V. Pipek, D. Randall, M. Rohde, K. Schmidt, \& G. Stevens (Eds.), Designing socially embedded technologies in the real-world (Vol. 1, pp. 243-278). Oxford: Oxford University Press. https:// doi.org/10.1093/oso/9780198733249.003.0008

Wauters, E., Donoso, V., \& Lievens, E. (2014). Optimizing transparency for users in social networking sites. Info, 16(6), 8-23. https://doi.org/10.1108/info-06-20140026

Yu, J., Stoilova, M., \& Livingstone, S. (2018, January 11). Regulating children's data and privacy online: The implications of the evidence for age-appropriate design. Media@LSE. Retrieved from https:// blogs.Ise.ac.uk/medialse/2018/11/01/regulatingchildrens-data-and-privacy-online-the-implicationsof-the-evidence-for-age-appropriate-design

Zimmerman, M. A. (2000). Empowerment theory. In J. Rappaport \& E. Seidman (Eds.), Handbook of community psychology (pp. 43-63). Boston, MA: Springer. https://doi.org/10.1007/978-1-4615-4193-6_2

\section{About the Author}

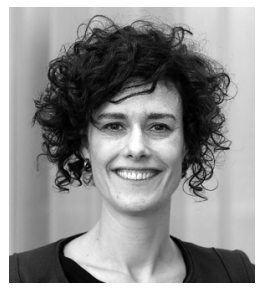

Bieke Zaman is Associate Professor and Head of the Meaningful Interactions Lab (Mintlab) at $\mathrm{KU}$ Leuven. Her research lies at the intersection of human-computer interaction research and communication sciences. Fascinated by the tech side of social, and the social side of tech, Zaman pursues research programs on Children, Media and Design, Media Convergence in a Digital Society, and Progressive Research and Dissemination Methods. 